\title{
Firing Behavior of the Clay Fraction of a Natural Kaolinitic Clay: Are They Different?
}

\author{
Carlos Maurício Fontes Vieira ${ }^{a}$, Sergio Neves Monteiro ${ }^{b *}$ (]) \\ ${ }^{a}$ Laboratório de Materiais Avançados, Universidade Estadual do Norte Fluminense Darcy Ribeiro, \\ RJ, Brasil. \\ ${ }^{b}$ Programa em Ciências dos Materiais, Instituto Militar de Engenharia, RJ, Brazil.
}

Received: February 22, 2019; Revised: August 14, 2019; Accepted: September 18, 2019

\begin{abstract}
A comparative investigation on the firing behavior of a natural kaolinitic clay from Campos dos Goytacazes, Brazil, and its specific clay fraction was performed. The clay fraction, equivalent diameter less than $2 \mu \mathrm{m}$, was separated from the precursor clay by a sedimentation method. Chemical analysis, X-ray diffraction (XRD) and scanning electron microscopy were used to characterize the unfired materials. Thermoanalysis and dilatometry were applied to follow the structural transformations. The firing behavior was studied by water absorption and XRD of samples fired in the temperature range from 400 to $1100^{\circ} \mathrm{C}$. Differences were found between the natural kaolinitic clay and its clay fraction. The absence of quartz and smaller particles of the clay fraction result in a comparatively lower temperature for structural consolidation associated with reduced open porosity. This can be attributed to solid state sintering alone, in contrast to a higher temperature liquid phase sintering needed for complete consolidation of the natural kaolinitic clay.
\end{abstract}

Keywords: Clay fraction, kaolinitic clay, firing, solid state sintering, liquid phase sintering, porosity.

\section{Introduction}

Clays are among the most widely investigated materials due to their extensive use, which covers from nuclear applications $^{1}$ to conventional ceramics for construction ${ }^{2-4}$. A natural clay is composed of minerals that have layer silicates as its main constituents ${ }^{5}$. The classic work of Pauling ${ }^{6}$ disclosed the structural characteristics and parametric relationships of these layer silicates, based on earlier X-ray diffraction investigations ${ }^{7,8}$. Today, this permits the conception of the well known atomic structure of clay minerals such as kaolinite, $\mathrm{Al}_{2} \mathrm{Si}_{2} \mathrm{O}_{5}(\mathrm{OH})_{4}$, with layers consisting of a silica tetrahedral sheet tied together with an alumina octahedral sheet. The concept of a clay mineral, as an essential constituent of a natural clay, was worked out several decades ago by $\mathrm{Grim}^{9,10}$. By that time, it had already been established that clays comprise extremely small particles, less than several microns in maximum diameter, of a few crystalline clay mineral compounds 5 . Moreover, it has been since verified that they are, in fact, relatively complex mixtures. Unless treatments are applied, it is almost impossible to obtain a chemically and mineralogically pure natural clay raw material ${ }^{11}$.

In addition to layer silicates, other non-clay minerals such as quartz, calcite and feldspar, as larger-sized particles, frequently occur in a natural clay and affect its properties. However, clay minerals largely control the physical, chemical and structural characteristics of a natural clay. As a practical consequence, clay minerals strongly influence the properties of clay-based ceramic products. In particular, the effective absorption of water molecules onto the surface of plate-shaped mineral particles is responsible for the considerable plasticity needed to form industrial clay bodies before firing ${ }^{9}$. The more clay minerals, the more plastic will be the clay body. Water serves not only as a medium to separate the particles and, thereby, to improve the viscous flow but also to hold particles together via hydrogen bonds ${ }^{5}$.

Another aspect that significantly influences the applied behavior of clay-based ceramics is the very small size of the clay mineral particles. For example, well-crystallized kaolinite particles are composed of hexagonal plates with equivalent micro diameter $<10 \mu \mathrm{m}$ and nanoscale, $<100 \mathrm{~nm}$, thickness ${ }^{12}$. Very small plate-shaped kaolinite particles can allow more water molecules to adhere to it. As a consequence, a kaolinite clay body is easily formed by press molding or extrusion processing.

The influence of the clay particle size, given by its equivalent spherical diameter, $\phi$, is so important that a triangular diagram was propose ${ }^{13}$ to evaluate the properties of clay bodies based only on their granulometric composition. This widely used granulometric diagram, shown in Fig. 1, indicates the body's particle size as a composition of three main size ranges: (a) $\phi<2 \mu \mathrm{m}$, (b) $2<\phi<20 \mu \mathrm{m}$; (c) $\phi>20$ $\mu \mathrm{m}$. Particles associated with the triangle vertice (corner) for which $\phi<2 \mu \mathrm{m}$, are known as the clay fraction of the body. While particles associated with the $2<\phi<20 \mu \mathrm{m}$ in Fig. 1 
are denoted as the silt fraction and with the $\phi>20 \mu \mathrm{m}$ corner, as sand fraction. The smaller particles at the $\phi<2 \mu \mathrm{m}$ corner are mostly plate-shaped clay minerals such as layer silicates as well as hydroxides that have secondary origin ${ }^{1,2}$. A natural clay normally consists of distinct minerals with different particle sizes associated with size ranges corresponding to a specific position within the granulometric diagram. In practice, a natural clay with particle size approaching the $\phi<2 \mu \mathrm{m}$ corner in Fig. 1, is considered excessively plastic. Such a clay would be difficult to process and prone to develop cracks after industrial firing at higher temperatures, usually above $900^{\circ} \mathrm{C}^{13}$. In this case, a non-plastic material such as sand with larger particle size, associated with the $\phi>20 \mu \mathrm{m}$ corner in Fig. 1, is usually added to displace the granulometric position of a plastic clay to a more central region in the diagram, which would be considered appropriate to conventional red ceramic product ${ }^{13}$.

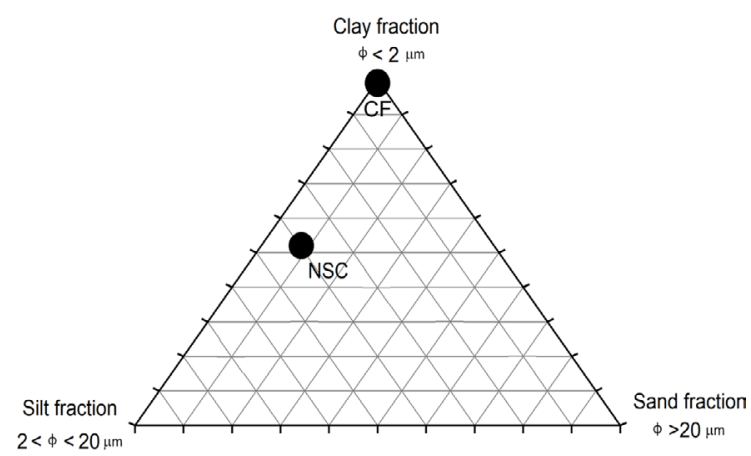

Figure 1. Clay body particles sizes diagram.

In a previous article ${ }^{14}$, it was shown that the plate-shaped, nanoscale thick layer silicate particles would allow for a much more efficient solid state sintering mechanism than the classical spherical particle model. Consequently, very plastic natural clays can be successful processed at temperatures as low as $600^{\circ} \mathrm{C}$ to fabricate ceramic pieces such as red bricks. In fact, the greater the plasticity of a clay, the more effective should be its consolidation at lower temperatures ${ }^{14}$.

According to the granulometric diagram, the highest plasticity would correspond to a clay body with particle size below $2 \mu \mathrm{m}$. This body is only composed of clay fraction and its location coincides with the $\phi<2 \mu \mathrm{m}$ corner of the diagram. The absence in nature of a pure clay fraction material hampers the direct investigation of what would be the most plastic clay. However, it is possible to simulate such a material by separating the particles with $\phi<2 \mu \mathrm{m}$ in any commonly occurring clay. Thus, the objective of the present work was to evaluate the firing behavior of a clay fraction separated from a typical natural kaolinitic clay. The characteristics and properties of this clay fraction were compared to those corresponding to its mother natural clay precursor.

\section{Materials and Methods}

The natural kaolinitic clay investigated in this work was obtained in a sedimentary alluvium deposit located in the region of Campos dos Goytacazes, northern region of the State of Rio de Janeiro, Brazil. This material corresponds to the most abundant type of clay collected from the upper stratum of the deposit, which is typically used for red ceramics fired at temperatures that vary from 600 to $1000^{\circ} \mathrm{C}$ depending on the final product ${ }^{15}$.

After collection, the clay was dried at $110^{\circ} \mathrm{C}$, manually crushed and then sieved to 20 mesh $(840 \mu \mathrm{m})$ before representative samples were separated by quartering. In particular, drying was extended for up to 6 hours until constant weight was attained. Even though the 20 mesh sieving and drying may eliminate some compounds, this natural kaolinitic clay will be referred as the natural silty clay. Indeed, the location of this clay (NSC) in the diagram of Fig. 1 reveals a position with approximately $50 \%$ clay fraction, $40 \%$ silt fraction and $10 \%$ sand fraction. It corresponds to the basic yellow kaolinitic clay used by the local industries ${ }^{15}$. The clay fraction (CF), $\phi<2 \mu \mathrm{m}$, of this natural silty clay was obtained by sedimentation method according to the Brazilian standard ${ }^{16}$. This sedimentation method was accomplished by dispersing the material in distilled water with addition of sodium hexametaphosphate and sodium carbonate. The solution was agitated for 15 minutes in a mixer and put into test tubes. The equivalent spherical diameter of the particles was calculated using Stokes' law. The non-sedimented solution after $24 \mathrm{~h}$, corresponding to the finer material (obtained as per NBR 71816), was finally dried and sieved to 200 mesh to eliminate larger agglomerates. Both the natural silty clay and its clay fraction were subjected to the following characterization techniques: X-ray diffraction (XRD), chemical composition, thermo and dilatometric analysis. The XRD of randomly oriented powder was carried out in a Sheifert model URD 65, diffractometer, equipped with a graphite monochromator, operating with $\mathrm{Cu}-\mathrm{K}_{\alpha}$ radiation for a $2 \theta$ range from $5^{\circ}$ to $40^{\circ}$. The chemical composition was carried out by fluorescence spectrometry in a Philips, PW 2400 equipment. The thermoanalysis, TGA and DTA, were conducted in a TA instrument model SDT 2960 using a $25 \mathrm{mg}$ powder sample operating under a $100 \mathrm{ml} . \mathrm{min}^{-1}$ flow of air and heating rate of $10^{\circ} \mathrm{C} / \mathrm{min}$. The dilatometric analysis was carried out on unfired test samples using an Orton dilatometer, at a heating rate of $5^{\circ} \mathrm{C} /$ min. The morphology of the clay fraction was studied by scanning electron microscopy (SEM) using a Zeiss model DSM 962 equipment.

To investigate the water absorption after firing, circular specimens $3 \mathrm{~cm}$ in diameter and with $8 \%$ humidity were prepared by uniaxial pressing at $20 \mathrm{MPa}$. This level of 
specimen pressing, commonly applied in advanced ceramic industries ${ }^{13}$, significantly improves particles packing and contributes to limit porosity. All specimens were dried at $110^{\circ} \mathrm{C}$ until constant weight was achieved. The firing of the specimens was performed at temperatures of 400 , $500,600,700,800,900,1000$ and $1100^{\circ} \mathrm{C}$ in a laboratory electric furnace. A controlled heating rate of $3^{\circ} \mathrm{C} / \mathrm{min}$ was maintained until the desired temperature was achieved. Each specimen was then left for three hours at this constant temperature. Cooling occurred by natural convection after turning the furnace off and leaving the specimen inside. Ten specimens for each composition were tested to obtain the water absorption, according to standard procedure ${ }^{17}$. The Weibull method was applied to provide a reliable statistical analysis for the water absorption results. For this purpose, the Weibull Analysis program was used considering the frequency distribution function, in which $\mathrm{x}$ corresponds to the water absorption measured value:

$$
F(x)=\exp \left[-\left(\frac{x}{\theta}\right)^{\beta}\right]
$$

where $\beta$ is the Weibull modulus, also known as "shape factor" and $\theta$ is the scale normalizing parameter. Equation (1) can be modified to adjust a linear graph:

$$
\ln \left[\ln \left(\frac{1}{F(x)}\right)\right]=\beta \ln x-(\beta \ln \theta)
$$

in which $\beta$ is the linear slope. A single slope is associated with a unimodal mechanism. The value of $\theta$ is related to the consistency of the water absorption measurements with precision given by the $\mathrm{R}^{2}$ parameter, which varies between zero and one, the best value.

Major crystalline phases were determined by XRD in sectioned pieces, collected from the center of fired specimens, according to the previously described procedures employed for the unfired materials. After 3 hours at the desired temperature, a fully homogeneous sintered structure was established from surface to core of the relatively small $3 \mathrm{~cm}$ specimens. By color and consistency, no evidence of inhomogeneity was observed, which could interfere with XRD results.

\section{Results and Discussion}

Figure 2 shows the XRD patterns of the natural silty clay and its clay fraction. One should notice that both spectra are composed of gibbsite, goethite and a micaceous mineral. The only difference is the absence of quartz in the clay fraction, which is an obvious consequence of its particle size being smaller than $2 \mu \mathrm{m}$. The micaceous mineral is probably associated with muscovite mica.

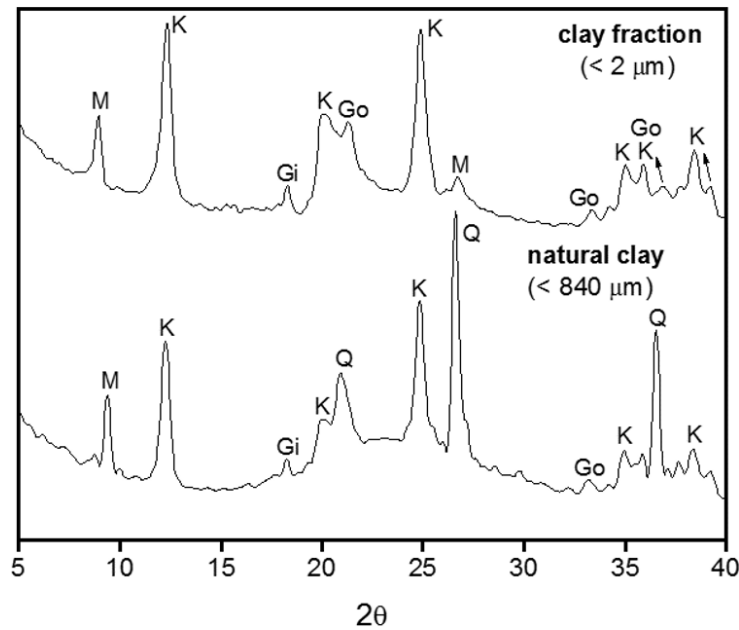

Figure 2. XRD patterns of the clay fraction and the natural clay. $\mathbf{G i}$ = gibbsite; $\mathbf{G o}=$ goethite $\mathbf{K}=$ kaolinite $\mathbf{M}=$ micaceous mineral; $\mathbf{Q}=$ quartz.

The SEM micrograph in Fig. 3 shows the morphological aspects of the clay fraction particles, probably kaolinite, with equivalent spherical diameter below $2 \mu \mathrm{m}$. In this figure, in addition to individual particles, plate-shaped aggregates are also observed. Some of the smaller particles are at nanometric scale. The irregular and pseudo-hexagonal plates of the kaolinite particles indicate their poorly crystallized nature. This SEM observation confirms the general morphological aspects of the clay fraction investigated, which is basically composed of plate-shaped particles or aggregates of nonometric thickness.

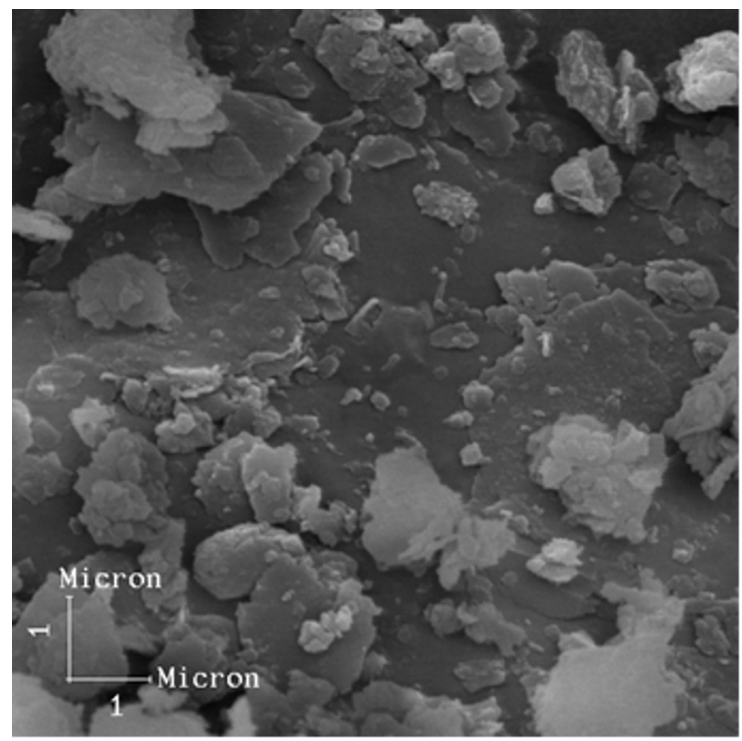

Figure 3. SEM micrograph of the clay fraction $(10.000 \mathrm{x})$.

The chemical analysis of both, the natural silty clay and its clay fraction are presented in Table 1. In this table, the theoretical composition of a pure kaolinite in terms of $\mathrm{SiO}_{2}$, 
$\mathrm{Al}_{2} \mathrm{O}_{3}$ and constitution water is also presented. It should be noted that the clay fraction shows a higher amount of clay minerals than the natural silty clay. The $\mathrm{SiO}_{2} / \mathrm{Al}_{2} \mathrm{O}_{3}$ ratio is an indicative of the amount of clay minerals and quartz. The theoretical 1.18 ratio is associated with pure kaolinite. Higher ratios indicate the presence of free quartz, as in the case of 1.54 for the natural silty clay. By contrast, the 1.16 ratio for the clay fraction, a little lower than the theoretical value for the kaolinite, corresponds to a small excess of $\mathrm{Al}_{2} \mathrm{O}_{3}$. This is explained by the presence of alumina in some mineralogical phases, such as the gibbsite, according to the XRD pattern shown in Fig. 2. The relatively large $\mathrm{Fe}_{2} \mathrm{O}_{3}$ content is similar in both the natural silty clay and its clay fraction, indicating that $\mathrm{Fe}$ is present in secondary minerals such as goethite, micaceous mineral and possible in the network of the clay minerals partially substituting the Al. The higher value of Loss on Ignition (LoI) for the clay fraction is related to the significant presence of clay minerals, associated with more constitution water, and the absence of free quartz. An important conclusion from the results in Table 1 is that the kaolinitic natural silty clay, which in practice may be considered a reasonably plastic material, has a sensibly different behavior from its clay fraction due to the presence of non-plastic quartz particles.

Figures 4 and 5 show the DTA/TG/DTG curves, simultaneously recorded during heating from 25 to $1125^{\circ} \mathrm{C}$, for the natural silty clay and its clay fraction, respectively. The DTA curve of the natural silty clay in Fig. 4, shows three endothermic peaks at $59.0^{\circ} \mathrm{C}, 267.0^{\circ} \mathrm{C}$ and $497.6^{\circ} \mathrm{C}$ and an exothermic one at $947.8^{\circ} \mathrm{C}$. These are well-known peaks for a kaolinitic clay ${ }^{15}$. A discrete endothermic peak can also be observed at temperatures around $575^{\circ} \mathrm{C}$ and is associated with the allotropic transformation of quartz- $\alpha$ to quartz- $\alpha^{18}$. In the DTG curve, three peaks, $55.6^{\circ} \mathrm{C}, 263.0^{\circ} \mathrm{C}$ and $496.9^{\circ} \mathrm{C}$, of weight loss are observed. They correspond to steps of weight loss in the TG curve. The weight loss of 1.82 wt. $\%$, for the first step from 25 to $160^{\circ} \mathrm{C}$, corresponding entirely to the first DTA endothermic peak, is related to the elimination of hygroscopic water. The weight loss of 2.93 wt. $\%$, for the second step from 225 to $360^{\circ} \mathrm{C}$ is associated with the decomposition of hydroxides, such as gibbsite and goethite (see Fig. 2). The weight loss of 8.28 wt. \%, for the third and most significant step from 360 to $800^{\circ} \mathrm{C}$, is associated with the kaolinite desidroxylation, forming the metakaolinite phase. In addition, the weight loss does not

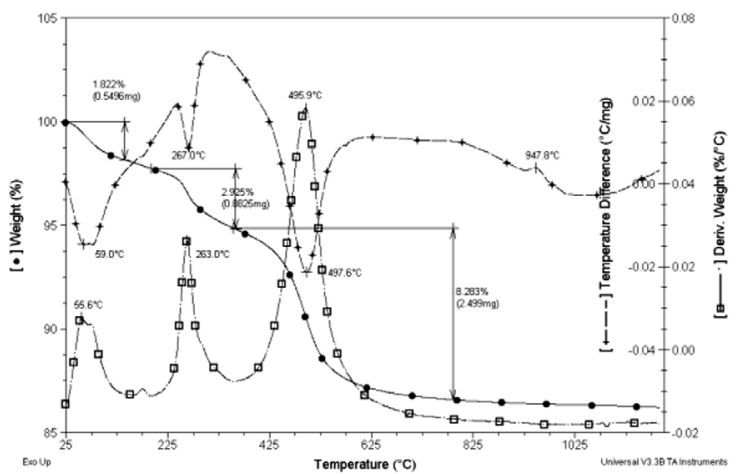

Figure 4. Thermal analysis curves (DTA/TG/DTG) of the natural silty clay.

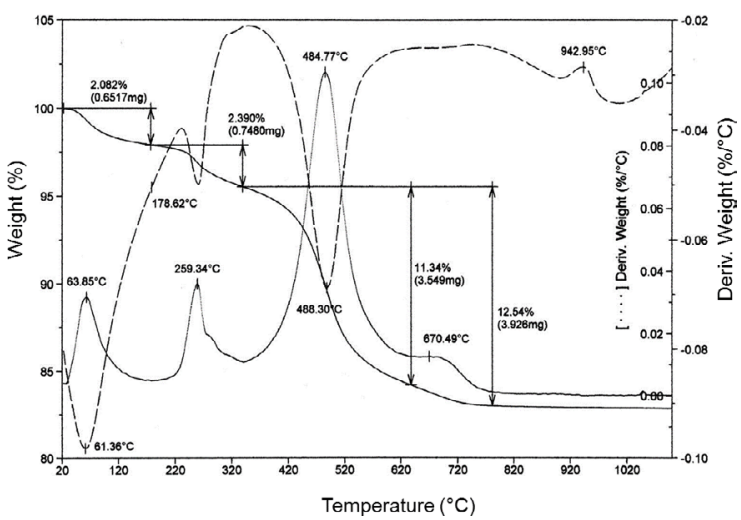

Figure 5. Thermal analysis curves (DTA/TG/DTG) of the clay fraction.

significantly change above $800^{\circ} \mathrm{C}$. The only exothermic DTA peak around $950^{\circ} \mathrm{C}$ has been associated with the metakaolinite decomposition, forming amorphous silica and spinel-type structure ${ }^{19}$.

In contrast to the natural silty clay, the thermal behavior of its clay fraction presents a higher weight loss, $11.34 \mathrm{wt} . \%$, associated with kaolinite desidroxylation. This confirms the relatively larger kaolinite content in the clay fraction. A small weight loss of $1.2 \%$ at $670.49^{\circ} \mathrm{C}$ in the DTG curve of the clay fraction, Fig. 5, is apparently another difference with respect to the natural silty clay. This could be attributed to the elimination of constitution water of micaceous mineral, which becomes relatively prominent in the clay fraction.

Figure 6 presents the dilatometric behavior from room temperature to $1300^{\circ} \mathrm{C}$ of the natural silty clay and its clay fraction. As expected with any heated clay body, both materials

Table 1. Chemical composition of the natural clay and its clay fraction (wt. \%).

\begin{tabular}{|c|c|c|c|c|c|c|c|c|c|c|}
\hline & $\mathrm{SiO}_{2}$ & $\mathrm{Al}_{2} \mathrm{O}_{3}$ & $\mathrm{Fe}_{2} \mathrm{O}_{3}$ & $\mathrm{TiO}_{2}$ & $\mathrm{~K}_{2} \mathrm{O}$ & $\mathrm{Na}_{2} \mathrm{O}$ & $\mathrm{CaO}$ & MgO & LoI & $\mathrm{SiO}_{2} / \mathrm{Al}_{2} \mathrm{O}_{3}$ \\
\hline $\begin{array}{l}\text { Natural Silty Clay } \\
(<840 \mu \mathrm{m})\end{array}$ & 44.56 & 29.64 & 8.72 & 1.22 & 1.40 & 0.51 & 0.34 & 0.89 & 11.40 & 1.54 \\
\hline $\begin{array}{l}\text { Clay Fraction } \\
(<2 \mu \mathrm{m})\end{array}$ & 38.80 & 33.58 & 8.97 & 1.11 & 0.88 & 0.29 & 0.25 & 1.06 & 13.83 & 1.16 \\
\hline $\begin{array}{l}\text { Theoretically Pure } \\
\text { Kaolinite }\end{array}$ & 46.56 & 39.50 & - & - & - & - & - & - & $\begin{array}{l}13.94 \\
\left(\mathrm{H}_{2} \mathrm{O}\right)\end{array}$ & 1.18 \\
\hline
\end{tabular}


undergo a general shrinkage process displaying negative peaks in the $d L / L_{0} d t$ corresponding to the maximum rate of sintering effect. In spite of this common shrinkage, significant differences are observed. The natural silty clay, after a small contraction of less than $2 \%$, begins an effective shrinkage process around $1000^{\circ} \mathrm{C}$, which results in a $10 \%$ contraction at $1300^{\circ} \mathrm{C}$. By contrast, the clay fraction after $1 \%$ of initial contraction begins its effective shrinkage around $800^{\circ} \mathrm{C}$. Moreover, at $1050^{\circ} \mathrm{C}$ the clay fraction reaches the shrinkage detection limit, $13 \%$, of the equipment. The sudden drop in $d L / L_{0}$ corresponding to an effective shrinkage can be related to the sintering process responsible for the consolidation of the ceramic structure ${ }^{20}$. By a similar reasoning, the maximum sintering rate can be associated with the peaks in the variation of $d L / L_{0} d t$ with the temperature displayed in Fig. 6. In the case of the natural silty clay, a maximum sintering rate occurs at $1125^{\circ} \mathrm{C}$ and $d L / L_{0} d t$ is still oscillating at lower values when the temperature limit, $1300^{\circ} \mathrm{C}$, of the equipment is reached. This is an indication that the sintering process has not yet been accomplished. Furthermore, evidence of partial vitrification was found at $1300^{\circ} \mathrm{C}$. On the contrary, the clay fraction shows a maximum sintering rate at a comparatively lower temperature, $890^{\circ} \mathrm{C}$, followed by shrinkage completion, $d L /$ $L_{0} d t=0$, around $1050^{\circ} \mathrm{C}$. The dilatometric results in Fig. 6 reveal the possibility of different consolidation mechanisms are occurring between the natural silty clay and its clay fraction. While the clay fraction, basically composed of plate-shaped nanometer thick particles, can be consolidated by a solid state sintering mechanism ${ }^{14}$, the natural silty clay needs additional liquid phase sintering to complete consolidation at higher temperatures ${ }^{21}$.

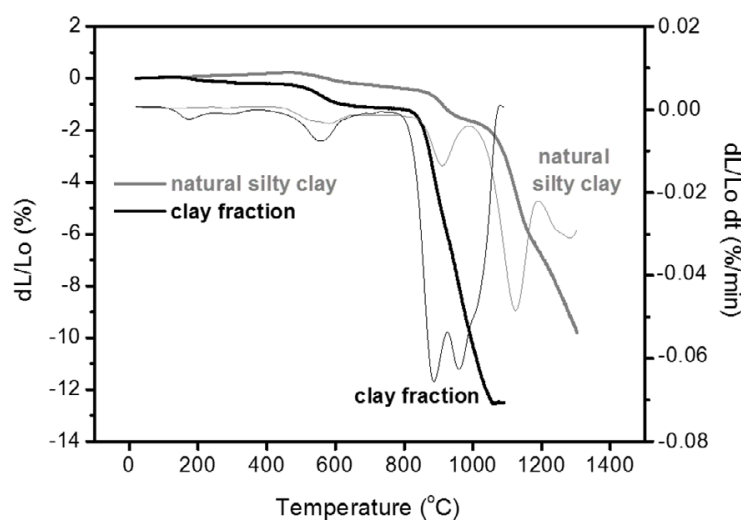

Figure 6. Dilatometric behavior of the natural silty clay and its clay fraction.

The water absorption of specimens fired at different temperatures is presented in Fig. 7. The Weibull distribution curves, for 10 specimens of each condition in Fig. 7, are depicted in Fig. 8 with corresponding parameters in Table 2. This Weibull analysis discloses consistent unimodal results associated with a single mechanism and relatively low dispersion of values. Both CF and NSC relatively higher shape parameters and consistent scale parameters, $\mathrm{Eq}(2)$, in association with $\mathrm{R}^{2}$ above 0.8337 . It should be noticed that, at any temperature, the water absorption of the natural silty clay is greater than that of its clay fraction. Furthermore, while the water absorption of the natural silty clay increases with the firing temperature up to $900^{\circ} \mathrm{C}$, that of its clay fraction decreases. This fact reveals important differences in firing behavior between the two materials. For instance, the natural silty clay fired at $400^{\circ} \mathrm{C}$ dissolved apart when put into contact with water during the test. This is a consequence of a weak particle consolidation, which probably extends up to $900^{\circ} \mathrm{C}$ even though the specimens remained intact above $400^{\circ} \mathrm{C}$. The increase in water absorption from 500 to $900^{\circ} \mathrm{C}$ for the natural silty clay is probably due to pores that are more open being formed, following water evolution as vapor during the kaolinite desidroxylation. This appears to be a more efficient mechanism than the normally expected closure of smaller pores during the initial stages of sintering ${ }^{22}$. By contrast, the clay fraction has already developed an apparently consolidated structure at temperatures as low as $400^{\circ} \mathrm{C}$, at which the specimen was intact and with a relatively low, 7\%, open porosity. Increasing the firing temperature, this consolidation, associated with the decrease in water absorption in Fig. 7, becomes even more effective. In the case of kaolinitic particles alone, which is practically the situation of the investigated clay fraction, solid state sintering by surface area contact is expected to begin above $400^{\circ} \mathrm{C}^{14}$. The complete dehydration and the activation of oxygen bonds associate with metakaolinite formation by dehydroxilation, favor surface bonding between particles ${ }^{9}$. This sintering mechanism apparently predominates over the open pore formation by water vapor evolution that also occurs during dehydroxilation of the clay fraction.

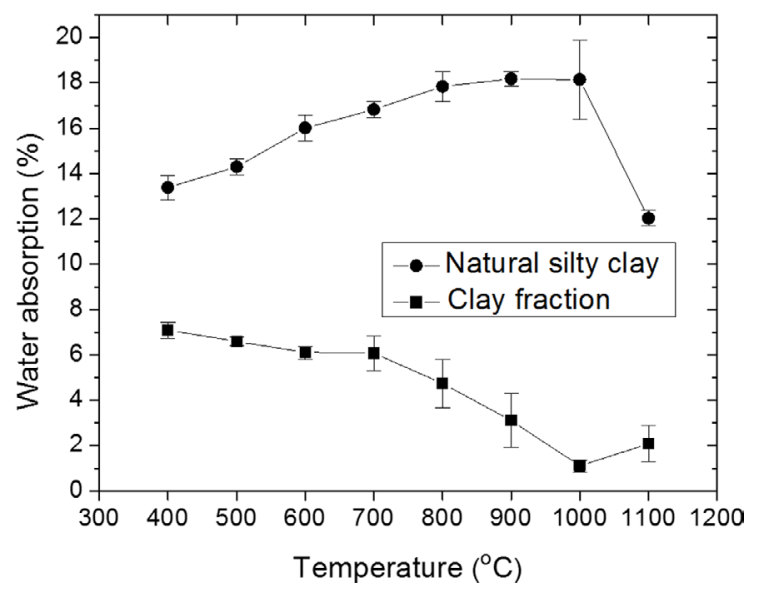

Figure 7. Variation of the water absorption as function of the firing temperature. 

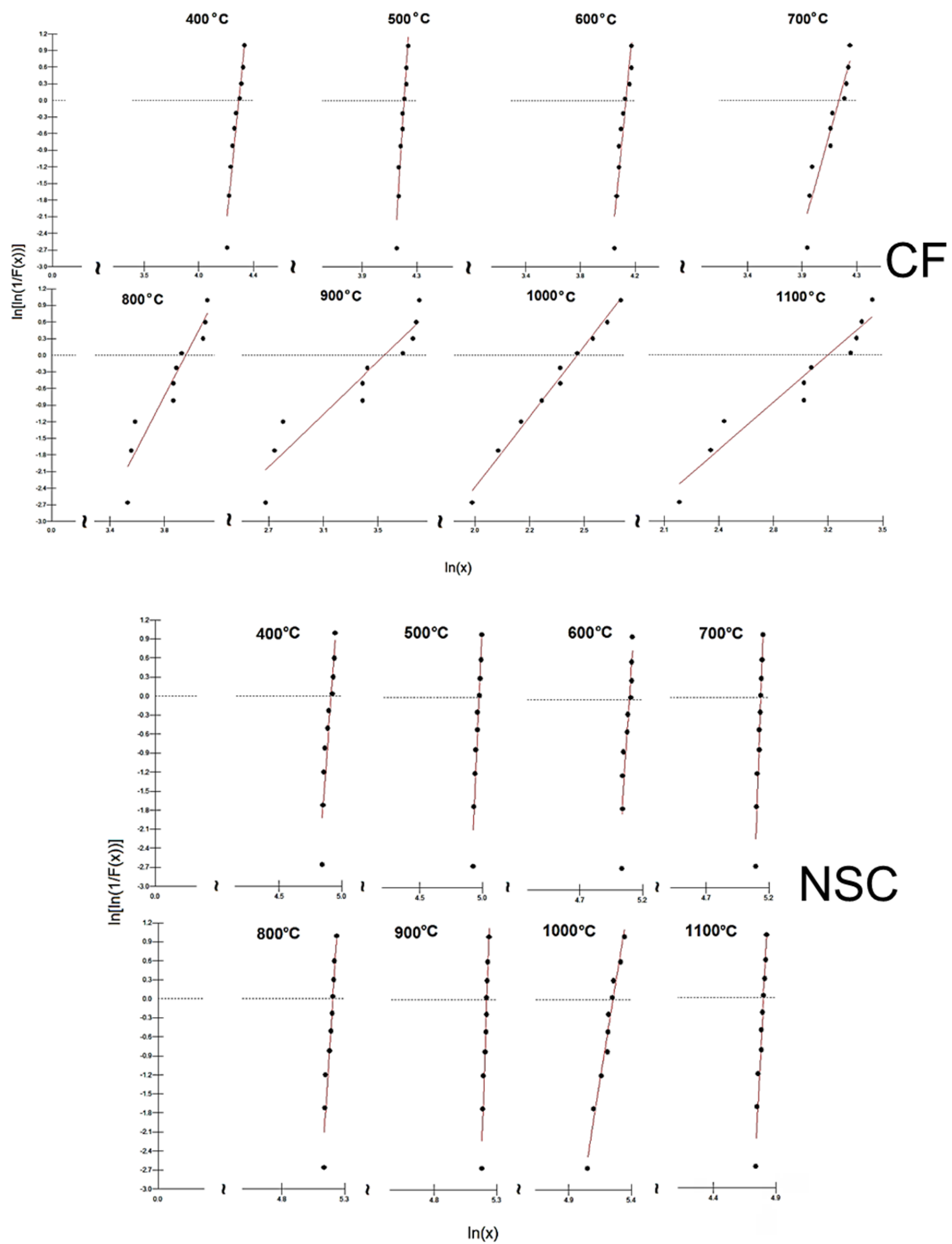

Figure 8. Weibull distribution curves for the water absorption results of clay fraction (CF) and natural silty clay (NSC) fired at different temperatures. 
Table 2. Weibull parameters for the water absorption of clay fraction (CF) and natural silty clay (NSC) fired at different temperatures.

\begin{tabular}{ccccccc}
\hline \multirow{2}{*}{$\begin{array}{c}\text { Firing } \\
\text { Temperature }\left({ }^{\circ} \mathbf{C}\right)\end{array}$} & $\boldsymbol{C}$ & $\mathbf{q}$ & $\mathbf{R}^{2}$ & $\boldsymbol{\beta}$ & \multicolumn{2}{c}{ NSC } \\
\hline 400 & 22.11 & 75.52 & 0.9432 & 26.84 & 136.4 & 0.9047 \\
500 & 36.34 & 66.83 & 0.9402 & 44.63 & 144.6 & 0.9435 \\
600 & 24.00 & 62.17 & 0.9084 & 29.48 & 162.6 & 0.8337 \\
700 & 8.20 & 64.11 & 0.9162 & 54.48 & 169.8 & 0.9771 \\
800 & 4.51 & 51.48 & 0.9144 & 29.49 & 181.5 & 0.9362 \\
900 & 2.43 & 35.01 & 0.9100 & 55.65 & 184.2 & 0.9595 \\
1000 & 4.54 & 11.99 & 0.9897 & 11.29 & 189.3 & 0.9744 \\
1100 & 2.44 & 23.36 & 0.9511 & 38.60 & 121.8 & 0.9700 \\
\hline
\end{tabular}

Regarding the results in Fig. 7, it should be mentioned that in the natural silty clay an effective consolidation process begins to occur only above $600-1000^{\circ} \mathrm{C}$, which is the normal condition for firing red ceramics ${ }^{14}$. At $1100^{\circ} \mathrm{C}$, the water absorption of the natural silty clay reaches $12 \%$, a value within the industrial specifications, for roofing tiles $^{23}$. This is a clear indication that the structure is partially consolidated, possibly by liquid phase formation that significantly reduces the open porosity. It should be also mentioned that a sudden decrease in water absorption, which occurs from 1000 to $1100^{\circ} \mathrm{C}$, is probably a consequence of the melting of alkaline silicates, Table 1, filling existing microstructural porosity. In comparison, the clay fraction discloses a much more efficient consolidation by solid state sintering that allows it to reach only $2 \%$ of water absorption at $1100^{\circ} \mathrm{C}$. The slight increase in the water absorption from 1000 to $1100^{\circ} \mathrm{C}$ probably indicates that total consolidation of clay fraction had already occurred. This is confirmed by the dilatometric result in Fig. 6.

Figures 9 and 10 show, respectively, the XRD patterns of the natural silty clay and its clay fraction fired at temperatures varying from 400 to $1100^{\circ} \mathrm{C}$. The striking difference between the XRD patterns of these figures is the presence of strong quartz $(\mathrm{Q})$ peaks in the natural clay and the complete absence in its clay fraction. This result corroborates those of Fig. 2 and Table 1 for the unfired materials indicating that quartz is the major mineralogical difference between them. For the other peaks in Figs 9 and 10, no significant differences were found. Actually, the transformations that occurred regarding the results in Fig. 2 were those expected in kaolinitic clay ceramics ${ }^{19}$. The gibbsite and goethite in the unfired materials disappeared due to their decomposition to form respectively, alumina (A) and hematite $(\mathrm{H})$. Above $500^{\circ} \mathrm{C}$, the kaolinite $(\mathrm{K})$ is no longer detected due to its desidroxylation to form the metakaolinite, an amorphous phase.

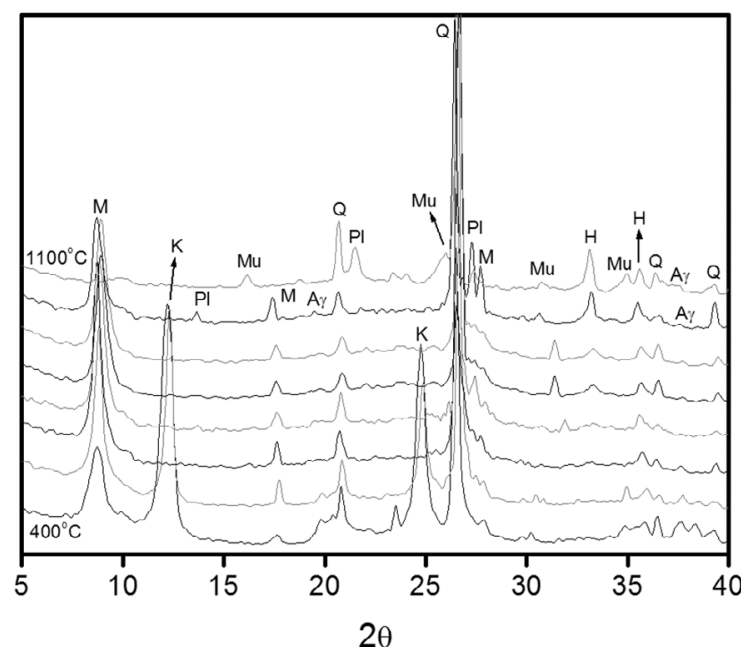

Figure 9. XRD patterns of the natural silty clay fired at temperatures from 400 to $1100^{\circ} \mathrm{C} . \mathbf{A}_{\gamma}=\gamma$-Alumina; $\mathbf{H}=$ Hematite; $\mathbf{K}=$ kaolinite; $\mathbf{M}=$ micaceous mineral $; \mathbf{M u}=$ mullite $\mathbf{P I}=$ plagioclases $; \mathbf{Q}=$ quartz.

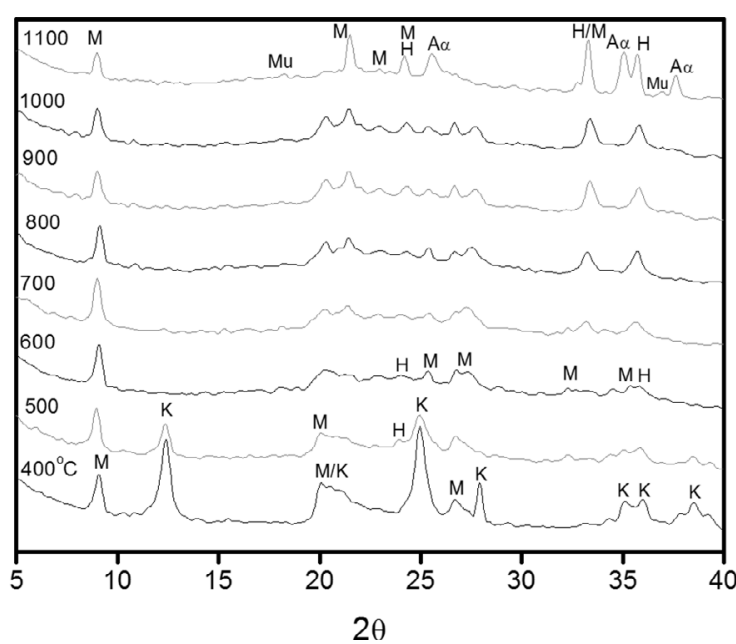

Figure 10. XRD patterns of the clay fraction fired at temperatures from 400 to $1100^{\circ} \mathrm{C} . \mathbf{A}=\alpha$-Alumina; $\mathbf{H}=$ Hematite; $\mathbf{K}=$ kaolinite; $\mathbf{M}=$ micaceous mineral; $\mathbf{M u}=$ mullite $; \mathbf{P I}=$ plagioclases; $\mathbf{Q}=$ quartz . 
At higher temperatures, mullite formed from the metakaolinite decomposition, was detected for both materials. However, the type of alumina was different for each material. In the clay fraction, the higher amount of gibbsite contributed to form alumina- $\alpha$ from its decomposition ${ }^{24}$. Contrary to this, in the natural silty clay alumina- $\gamma$ appears from the metakaolinite decomposition ${ }^{19}$. In the particular case of the clay fraction, Fig 10, the lower intensity of the crystalline phases and the absence of alumina- $\gamma$ are probably associated with a greater amount of amorphous phase, which may be attributed to the absence of quartz and a consequent relatively larger kaolinite content.

As a final remark, it is relevant to comment that the present investigation was carried out on a specific natural kaolinitic clay and its clay fraction. Other clays with distinct mineralogical compositions may not give the same results. However, the firing behavior of any clay fraction, with $\phi<2 \mu \mathrm{m}$ plate-shaped particles and nanometer thickness, has to be different from its precursor natural raw clay. In particular, a solid-state sintering mechanism ${ }^{14}$ should provide a significantly lower temperature for any clay fraction structural consolidation. This should also be associated with a comparatively lower porosity, with a tendency to decrease, even further, the amount of pores above $400^{\circ} \mathrm{C}$. The final consolidation of the ceramic structure of a clay fraction body should not depend on liquid phase sintering, which is not the case of any natural raw clay. As a practical consequence, the greater the plasticity of these raw clays, the lower the temperature at which they should begin structural consolidation. Moreover, unless they are composed of clay minerals alone, their complete consolidation through vitrification will necessarily involve liquid phase sintering.

\section{Conclusions}

The comparative evaluation of the firing behavior of a natural kaolinitic silty clay from Campos dos Goytacazes, Brazil, and its clay fraction separated by sedimentation method, has led to the following conclusions.

- In the unfired materials the only mineralogical difference is the absence of quartz in the clay fraction. The firing process, in addition to the well-known transformations, confirms the absence of quartz in the clay fraction. Other differences in the X-ray patterns and thermoanalysis, could be attributed to the relatively larger amount of kaolinite in the clay fraction.

- Dilatometric results showed that the natural silty clay begins an effective consolidation process at temperatures $200^{\circ} \mathrm{C}$ above that of its clay fraction. Moreover, the sintering process in the clay fraction is apparently over at $1150^{\circ} \mathrm{C}$, while that of the natural silty clay is still not completed at $1300^{\circ} \mathrm{C}$.
- A significant difference occurred with the variation of water absorption with the firing temperature. The natural silty clay dissolves in water after being fired at $400^{\circ} \mathrm{C}$ and developed an increasing open porosity up to $1000^{\circ} \mathrm{C}$. By contrast, its clay fraction is already consolidated at $400^{\circ} \mathrm{C}$, by solid state sintering mechanism, which helps to decrease the open porosity with firing temperature. Liquid phase formation is probably needed to consolidate the natural silty clay structure but not its clay fraction at higher temperatures.

\section{Acknowledgements}

The authors would like to thank CNPq (proc. 150444/20036), CAPES, FAPERJ and FENORTE, for supporting this investigation.

\section{References}

1. Herrera MS, Hernandez MF, Cipollone M, Conconi MS, Rendtorff NM. Thermal behavior of samarium-oxide ball clay mixtures for high microscopic neutron cross section ceramic materials. Applied Clay Science. 2018;168:125-135.

2. Ribeiro MN, Lima ES, Figueiredo ABD, Amaral LF, Monteiro $\mathrm{SN}$, Vieira CMF. Improved clay ceramics incorporated with steelmaking sinter particulates. Journal of Materials Research and Technology. 2018;7(4):612-616.

3. Al-bared MAM, Marto A, Latifi N, Horpibulsuk S. Sustainable improvement of marine clay using recycled blended tiles. Geotechnical and Geological Engineering. 2018;36(5):31353147.

4. Savazzini-Reis A, et al. Characterization and evaluation of ceramic properties with spherical and prismatic samples of clay used in red ceramics. Materials Research. 2017;20(Suppl 2):543-548.

5. Callister Junior WD, Rethwisch DG. Materials Science and Engineering. An Introduction. $9^{\text {th }}$ ed. New York: John Willey \& Sons; 2014

6. Pauling L. Structure of micas and related minerals. Proceedings of the National Academy of Sciences. 1930;16:123-129.

7. Adding A. X-ray diffraction method of identification of crystalline and kripto-crystalline substances. Zeitschrift für Kristallographie. 1923;58:108-112.

8. Rinne F. An X-ray investigation of some finely divided minerals, artificial products and dense rocks. Zeitschrift für Kristallographie. 1924;60:55-69.

9. Grim RE. Applied Clay Mineralogy. New York: McGraw Hill Book; 1962.

10. Grim RE. The clay mineral concept. Ceramic Bulletin. 1965;44(9):687-692.

11. Castelein O, Soulestin B, Bonnet JP, Blanchart P. The influence of heating rate on the thermal behavior and mullite formation from a kaolin raw material. Ceramics International. 2001;27(5):517522 . 
12. Verduch AG. Origin and composition of ceramic clays. Boletín de la Sociedada Española de Cerámica y Vidro. 1985;24:395404.

13. Fancincani E. Ceramic Technology of Tiles. Barcelona: Faenza Editrice Ibérica S.L.; 1993.

14. Monteiro SN, Vieira CMF. Solid state sintering of red ceramics at lower temperatures. Ceramics International. 2004;30(3):381387.

15. Monteiro SN, Vieira CMF. Characterization of clays from Campos dos Goytacazes, North Rio de Janeiro State (Brazil). Tile \& Brick Intl. 2002;18(3):152-159.

16. Brazilian Association for Technical Norms (ABNT). Determination of granulometric analysis of soils - NBR 7181. Rio de Janeiro: ABNT; 1984.

17. American Society for Testing and Materials (ASTM). Water Absorption, Bulk Density, Apparent Porosity, and Apparent Specific Gravity of Fired Whiteware Products. West Conshohocken: ASTM International; 1972.
18. Barba A, Beltrán V, Feliu C, García J, Ginés F, Sánchez E, Sanz V. Raw materials for fabrication of supports to clay ceramics. Castellón: AICE/ITC; 1997.

19. Carty W, Senapati U. Porcelain-raw materials, processing, phase evolution and mechanical strength. Journal of the American Ceramic Society. 1998;81(1):3-20.

20. Gomes CF. Clays - what are and for what serve. Lisboa: Fundação Calouste Gulbenkian; 1988.

21. Kingery WD, Bowen HK, Uhlmann DR. Introduction to Ceramics. $2^{\mathrm{a}}$ ed. New York: John Wiley \& Sons; 1976.

22. Cultrone G, Sebastián E, Elert K, Torre OMJ, Cazalla C, Rodríguez-Navarro C. Influence of mineralogy and firing temperature on the porosity of bricks. Journal of the European Ceramic society. 2004;24:547-612.

23. Brazilian Association for Technical Norms (ABNT). Roofing tiles type romain - NBR 13582. Rio de Janeiro: ABNT; 1996.

24. Wefers K, Misra C. Oxides and Hydroxides of Aluminum - ALCOA. $19^{\text {th }}$ ed. Pittsburgh, PA: Laboratories Aluminum Company of America; 1987. 